\title{
Molecularly Imprinted Polymers: Promising Tool for the Human Virus Detection
}

\author{
Muhammad Shahzeb Khan ${ }^{1 *}$, Muhammad Ibrar Asif ${ }^{1}$, Amina Khatoon ${ }^{1}$, \\ Shafia $\mathrm{Arshad}^{2}$, Shagufta Usman ${ }^{3}$ and Iqra Karim ${ }^{4}$ \\ ${ }^{1}$ Sulaiman Bin Abdullah Aba Al-Khail Centre for Interdisciplinary Research in Basic Sciences, International Islamic \\ University Islamabad, Pakistan. \\ ${ }^{2}$ Faculty of Medicine and Allied Health Sciences, Islamia University Bahawalpur, Pakistan. \\ ${ }^{3}$ Faculty of Pharmaceutical Sciences, Riphah International University Islamabad, Lahore Campus, Pakistan. \\ ${ }^{4}$ Department of Chemistry, COMSATS University Islamabad, Lahore Campus, Pakistan. \\ *Corresponding Author Email: mshahzebkhan006@gmail.com \\ Received 01 March 2021, Revised 01 November 2021, Accepted 06 December 2021
}

\begin{abstract}
Molecular imprinting is an attractive research area for synthesizing unique functional polymers with high selectivity due to template oriented active sites. Molecularly imprinted polymers (MIPs) have a wide range of applications in chemical and biological sensing, drug delivery, and solidphase extraction owing to mechanical stability, reversibility, reproducibility, and cross-validity. MIPs are compatible with natural antibodies and are being used as antibody mi mics/receptors in the biomedical field. Today, viral detection is the most popular research area due to emerging viral diseases with genetic variability and drug resistance. Therefore, there is a need to control viral infections by discriminative recognition of the viral pathogens. This review summarizes the literature on the detection of human viruses by using MIPs.
\end{abstract}

Keywords. Molecularly imprinted polymers, human viruses, viral detection

\section{Introduction}

Viral infections are infecting the world due to their emergence and rapid spread from one region to another. Despite many efforts to control viral infection, it is still a major threat to the human population because of rapid spread and genetic variability [1-5]. Every year, 17 million deaths are caused due to viral infectious diseases [6]. It is challenging to control the viral disease because of the genetic variability, multi-resistant pathogen, absurd use of antibiotics, and rapid transmission [7, 8]. Timely and selective diagnosis following targeted vaccination can be useful to control viral infectious diseases. Some diagnostic techniques that are under practice for the laboratory diagnosis of the viral infectious disease are polymerase chain reaction (PCR), enzyme-linked immunosorbent assay (ELISA), chest CT, microscopy, and culture [9-14]. Several disadvantages are associated with these techniques, including complexity, time-consuming, non-economical, nonportable, and required sample preparation [15]. There are also some biosensors and bioassays that are present to detect viral pathogens, but there is a need for cheap, portable, and reusable biosensors for the sensitive and selective detection of various viral pathogens [16, 17]. Recently, molecularly imprinted polymers (MIPs) are being prepared by the utilization of molecular imprinting technology, which is compatible 
with natural antibodies owing to their unique characteristics. MIPs have specific imprinted cavities that bind only specific template molecules of interest, like a lock and key model [18]. Functional monomers interact with the templates, and a pre-polymerized complex is formed. The polymer matrix is obtained by adding porogenic solvents, crosslinker, and initiator. The polymer matrix is washed with an appropriate solvent to eliminate the template molecule to generate a size identical imprint of the target molecule $[19,20]$. MIPs are being used in the sensing and separation ranging from macro to micromolecules because of their excellent features. MIPs not only bind the template molecule but also possess tolerance to mechanical stress, elevated temperature, $\mathrm{pH}$, and acid-base environments [21]. MIPs are appropriate for various kinds of applications such as recognition receptors for chemical biosensors, mock elements for drug analysis, chromatographic separation media, solidphase extraction, plastic antibodies, and drug delivery Imprints of a vast range of the templates have been generated such as serotonin, urea, salbutamol, glucose, gallic acid, hydrazone, atrazine, cefalexin, testosterone, bilirubin, prostate cancer cell streaks, paclitaxel, uric acid, valganciclovir, various metals, and volatile organic compounds [20, 22-27]. Figure 1 represent the schematic illustrations for the synthesis of MIPs.

Viruses can mutate and produce new variants, which cause reinfection and fast transmission of the virus. Therefore, a fast and selective diagnosis of the viral infection is needed to control and treat the disease. MIPs are the artificial receptors for the detection of emerging virus infections compatible with natural antibodies due to their high sensitivity, selectivity, portability, low cost [28, 29]. In this review, we shall focus on the surrounding literature related to the recognition of human viral pathogens by utilizing the MIPs.

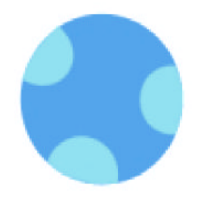

Template molecule

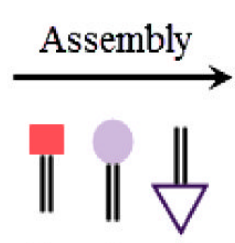

Functional monomers

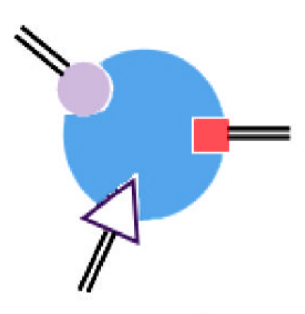

Pre-complex

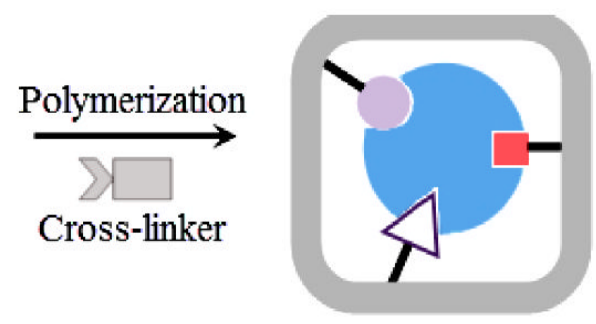

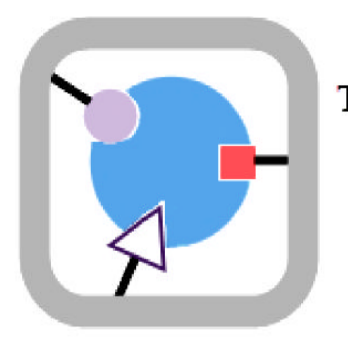

Figure 1. Fabrication mechanism of MIPs [18]

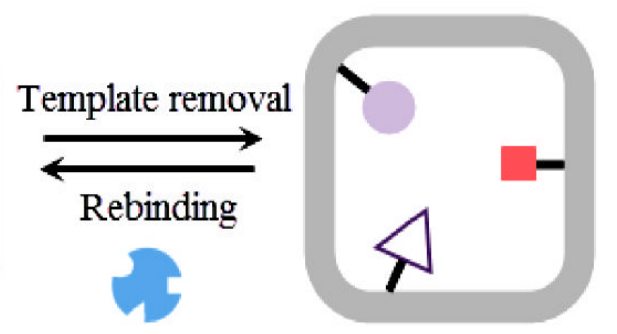

Molecularly imprinted polymer 


\section{Dengue Virus}

Dengue is a mosquito-borne disease that affects the human population worldwide. Dengue virus has become a major health threat to the public because of its viral genetic variation and transmission [30]. According to WHO, 100-400 million people get infected annually by the dengue virus [31]. There are severe clinical problems caused due to nonspecific demonstration leading to misdiagnosis of the infection. The development of the dengue disease vaccine is still in progress. Therefore, there is a need for fast disease diagnoses and patient management [32]. Sukjee et al. reported the imprinted polymer composite to recognize the dengue virus. Hummer's method was used to synthesize Graphene oxide (GO). The polymer was generated by mixing the methyl methacrylate (MMA), methacrylic acid (MAA), acrylamide (AAM), and nvinylpyrrolidone (NVP). The GO sheets and polymer were assorted to obtain a polymer composite with enhanced sensitivity. The polymer/GO composite was spin-coated on the gold electrode; the dengue virus and BPA template were plunged on the thin polymer film. The polymerization further proceeded under UV light for 2 hours at $55{ }^{\circ} \mathrm{C}$. Non imprinted polymer (NIP) based sensor was also synthesized to compare the response. The response of the electrochemical sensor was linear towards BPA concentration. The sensitivity response of the imprinted polymerbased sensor was high than the non-imprinted based sensor with the lowest detection limit of $0.1 \mathrm{pM}$ due to template oriented cavities within the polymer matrix [33]. Table 1 summarizes the MIP based sensors for the detection of dengue virus.

Rabia et al. reported MIP based impedance sensor for the detection of the dengue virus. Firstly, a mixture of dopamine hydrochloride and NS1 protein was formed, and $20 \mu \mathrm{L}$ of the mixture was placed on polysulfone-modified Screen-printed carbon electrodes (SPCEs), and polymerization continued. The electrode (SPCE/PS/NS1/DA) was treated with buffer after the polymerization. MIP modified electrodes were treated at various concentrations of NS1 protein to evaluate the sensitivity and selectivity response. Electrochemical impedance spectroscopy (EIS) and cyclic voltammetry $(\mathrm{CV})$ were used to measure the electrochemical response of MIP based sensor. The sensor exhibited a linear impedimetric response from 1 to $200 \mathrm{ng} / \mathrm{mL}$ with the LOD of $0.3 \mathrm{ng} / \mathrm{mL}$. Real human serum samples were also tested with the developed sensor to determine the NS1, and adequate recoveries altering from 95 to 97.14\% were attained [34]. Lieberzeit et al. reported a MIP-based QCM sensor for the detection of the dengue virus. The polymer was synthesized by using MAA and NVP monomers and cross-linker EGDMA. Dengue virus imprint was generated into the polymer matrix through molecular imprinted technique and NIP was also synthesized to compare the response. MIP response was 3 times higher than the NIP response with linearity curve [35].

Table 1. MIPs for Dengue virus detection.

\begin{tabular}{ccccccc}
\hline \multicolumn{1}{c}{ Virus } & Template & $\begin{array}{c}\text { Functional } \\
\text { Monomer }\end{array}$ & $\begin{array}{c}\text { Porogenic } \\
\text { solvent }\end{array}$ & Transducer & Detection limit & Ref \\
\hline Dengue virus & BPA with dengue & MMA, MAA, NVP & - & Electrochemical & $0.1 \mathrm{pM}$ & {$[33]$} \\
Dengue virus & Dengue NS1 protein & Dopamine & DMF and THF & Electrochemical & $0.3 \mathrm{ng} / \mathrm{mL}$ & {$[34]$} \\
\hline
\end{tabular}




\section{Influenza Virus}

Influenza, commonly named flu, is caused by viruses, belongs to the orthomyxoviridae family. Influenza viruses comprise a single-stranded negative RNA genome that encodes eleven proteins [13, 36]. The Orthomyxoviridae family has four types of influenza virus genera: A, B, C, and D. This classification is based on the matrix and internal glycoprotein nucleoprotein. A, B, and $\mathrm{C}$ genera generally infect human beings and cause significant illness and death per annum, whereas D type only infects cattle. Type A virus is among the most concerning type of viruses because it is responsible for severe seasonal epidemics [37]. Nearly $80 \%$ of influenza virus surface contains neuraminidase (NA) and glycoproteins hemagglutinin (HA) [38, 39].

Every year both A and B type causes deaths of nearly 30,000 to 50,000 persons while 200,000 people are hospitalized. Influenza is a leading cause of death after AIDS because approximately $5-15 \%$ of global population deaths occur per annum estimated by WHO. H1N1 and H3N2 subtypes also caused four major pandemics: Spanish flu, Asian flu, Hong Kong flu, and H1N1 pandemic in 1918, 1958, 1968, and 2009, respectively [13, 41]. MIPs are being used as selective bio mimics for the detection of the influenza virus. Five different MIPs QCM based sensors were generated by using five common strains of influenza A ( $\mathrm{H} 5 \mathrm{~N} 1$, H5N3, H1N1, H1N3, and H6N1).
Wangchareansak et al. used various monomers having concentrations as $13.0 \mathrm{mg}$ acrylamide, $10.6 \mathrm{mg}$ methacrylic acid, $6 \mathrm{mg}$ methylmethacrylate, and $6.3 \mathrm{mg} \mathrm{N}$ vinylpyrrolidone were mixed into a crosslinker which is $48 \mathrm{mg} \mathrm{N}, \mathrm{N}$-(1,2-dihydroxy ethylene) bisacrylamide. The solvent used in this method was $300 \mathrm{~mL}$ DMSO, and $1 \mathrm{mg}$ AIBN was used as an initiator. After that ability of MIP to detect template viruses was measured by using QCM [38]. QCM was used to measure the ability of molecularly imprinted polymer to absorb H5N1. These MIPs were used to identify inhibitors that can bind to the host receptors and obstruct virus function by making conformational changes [42]. Figure 2 shows the gravimetric detection of influenzas viruses.

MIPs as plastic antibodies were designed by Sangma et al. and used as copolymer systems for the detection of $\mathrm{H} 5 \mathrm{~N} 1$. This copolymer system is comprised of four types of monomers, including AAM, MAA, MMA, and vinylpyrrolidone [43]. Table 2 summarizes the MIP based sensors for the detection of the influenza virus.

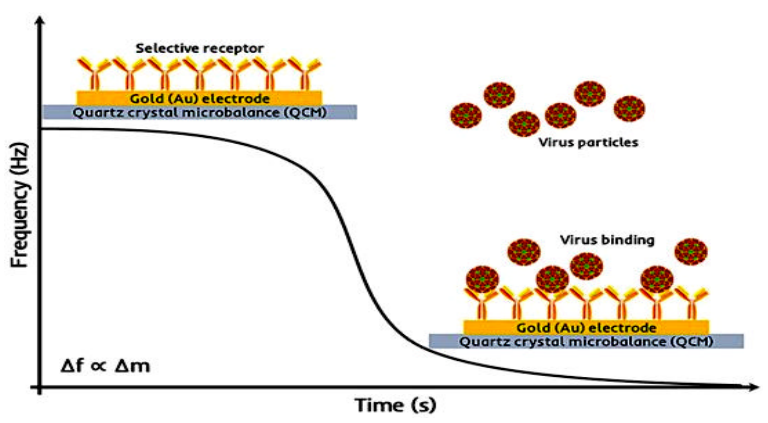

Figure 2. QCM based detection of influenzas viruses [40]

Table 2. MIPs for the detection of infl uenza.

\begin{tabular}{cccccccc}
\hline Virus & Template & Functional monomer & Crosslinker & Initiator & $\begin{array}{c}\text { Porogenic } \\
\text { sol vent }\end{array}$ & Transducer & Ref \\
\hline Influenza & $\begin{array}{c}\text { H5N3, H1N3, } \\
\text { H6N1 }\end{array}$ & $\begin{array}{c}\text { AAM, MAA, MMA, } \\
\text { Vinylpyrrolidone }\end{array}$ & DHEBA & AIBN & (DMSO) & QCM & {$[38]$} \\
Influenza & H5N1 & $\begin{array}{c}\text { AAM, MAA, MMA, } \\
\text { Vinylpyrrolidone }\end{array}$ & AIBN, DHEBA & AIBN & DMSO & QCM & {$[43]$} \\
Influenza & H1N1 & $\begin{array}{c}\text { AAM, MAA, MMA, } \\
\text { Vinylpyrrolidone }\end{array}$ & EGDMA, DHEBA & AIBN & DMSO & QCM & {$[44]$} \\
\hline
\end{tabular}


New granular MIP was synthesized by Sukjee et al. through precipitation polymerization using the influenza A virus as a template. The selective binding of influenza virus to molecularly imprinted polymer was measured after that, it was compared with other viruses. An agglutination test was done to check the affinity of the virus towards MIP. The MIP formed using the H1N1 template displayed specific reactivity, while the MIP formed using $\mathrm{H} 5 \mathrm{~N} 1$ and $\mathrm{H} 3 \mathrm{~N} 2$ templates exhibited cross-reactivity [44].

\section{Hepatitis}

It is a cluster of infectious diseases, and it is caused by hepatitis A, B, C, and D. Same disorder caused by these four types is liver function damage. These four types of viruses can also infect each other and live together in inpatient production with great complications. Hepatitis A virus and hepatitis $B$ virus are the most common type [41].

\section{HA V}

Hepatitis A virus (HAV) is a chief public health problem, and significantly it is a human pathogen. HAV is spread by the fecaloral route and by contact with the infected person HAV causes liver inflammation, and contaminated food is a common mode of Hepatitis A infection. The long-lasting liver infection causes a patient's death by sudden liver failure [45].

Upon clinical presentation, HAV cannot be distinguished from other hepatitis viruses due to structural similarities. Molecularly imprinted polymers have been proved very useful for HAV detection because of highly selective HAV detection. Another study showed that for precise identification and similar virus detection, molecular imprinting technology was a promising tool, while Quantum dots (QDs) were used to accomplish this goal. Green QDs@MIP and red QDs@MIP were produced by imprinting two different viruses on two different imprinting substrates. The hydrophilic group $\mathrm{N}$-isopropyl acrylamide and zinc acrylate as a functional monomer were added to improve recognition ability to discriminate similar viruses. This strategy not only determined target viruses but also distinguished two viruses by mixing two different types of MIPs. Visual recognition by the naked eye was done with the help of fluorescence core selection, which is based upon large stokes shift and manageable emission wavelength of quantum dots [45]. For precise diagnosis, Yang et al. designed a new core-shell molecular imprinted nanoparticles having PDA capped with silicon dioxide SiO2@PDA. These novel core-shell HAV-imprinted nanoparticles showed some properties to the HAV template like hydrophilic, specific recognition, and biocompatibility. Resonance light scattering (RLS) and fluorescence spectrophotometer was used for specific recognition and detection, respectively. The light scattering of this novel core-shell depends upon HAV concentration. Greater HAV concentration greater will be light scattering and vice-versa. It also showed an excellent selectivity towards HAV-virus. This novel HAV-imprinted SiO2@PDA nanoparticles were successfully used for the detection of HAV in real serum. This method combined MIP and RLS. The advantages of this novel sensor were high selectivity, best sensitivity, low cost, simplicity, and excellent biocompatibility [46]. Another novel RLS sensor was designed on a silica surface using thermosensitive imprinted polymer and $\mathrm{N}$ - isopropyl acrylamide as a temperature-sensitive element. By using this sensor, selection detection of the HAV was demonstrated, and its recognition ability was regulated by temperature control. This sensor was highly selective, eco-friendly, short response time, simple, sensitive, and facile [47]. 


\section{HBV}

Hepatitis B virus (HBV) causes about eight hundred thousand deaths annually because of cirrhosis and liver cancer. It is considered a major disease of humankind [48, 49]. HBV is highly contagious, spread by sexual activity, unsafe medical treatments, and transmitted from mother to child [48]. It is an extremely common infection in the world. About $15-40 \%$ of chronically infected persons will have hepatocellular carcinoma, cirrhosis, and liver failure, while $15-25 \%$ will die [48]. There are about eight major HBV genotypes in human beings. HBV genotype $\mathrm{C}$ is related to liver fibrosis and hepatocellular carcinoma [50]. HBV genome contains three thousand and twenty nucleotides long, and it consists of partially double-stranded DNA [51]. Similarly, the red MIP was synthesized by the same procedure (previously reported the synthesis of green MIP) by using the same chemicals with the same ratio except for the template, which is HBV in this case. The best amounts of EGDMA, zinc-acrylate, TEOS, and NIPAAm for R-MIP were $150 \mu \mathrm{L}, 40 \mathrm{mg}$, $300 \mu \mathrm{L}$, and $20 \mathrm{mg}$, respectively [45].

\section{$\mathrm{HCV}$}

Patients having acute Hepatitis $\mathrm{C}$ virus (HCV) infection develop chronic infection and a high risk of liver fibrosis progression. Advancement in alanine aminotransferase (ALT) is a significant predictor for enlargement and progression of liver fibrosis during chronic HCV infection. A novel sensor was designed for the detection of $\mathrm{HCV}$ core antigen by combining aptasensing, and MIP methodologies founded on electropolymerization of dopamine (DA) around the Apt [HCV core antigen] complex on MWCNTs-Chit modified GCE. It is a suitable method for HCV detection with high stability, low cost, best sensitivity, and short response time. CV, DPV, EIS are some electrochemical techniques that were used for measuring analytical performance [52].

\section{HEV}

Hepatitis E virus (HEV) is one of five known hepatitis viruses, and it was discovered after the hepatitis epidemic occurred in the early 1980 s because this virus caused the epidemic. There are several genotypes, and it was revealed after molecular characterization. Infections in human beings are caused by HEV genotype 1 HEV1, HEV2, HEV3, and HEV4 [53]. HEV1 and HEV2 are prevalent in developing regions, while HEV3 and HEV4 are observed in developed regions. HEV mainly spreads through the food chain and by eating meat from infected animals. It causes liver failure, chronic hepatitis, and cirrhosis [53]. HEV3 is responsible for causing hepatitis E [53]. Various MIP based sensors for the Hepatitis virus are summarized in Table 3.

Table 3. MIPs for Hepatitis virus detection.

\begin{tabular}{lcccc}
\hline Disease & Template & Linear Range & LOD & Detection method \\
\hline Hepatitis & HAV & $0.04-6.0 \mathrm{nmol} / \mathrm{L}$ & $8.6 \mathrm{pM}$ & MIPs-RLS sensor \\
Hepatitis & HAV & $0.3-95 \mathrm{nmol} / \mathrm{L}$ & $3.4 \mathrm{pmol} / \mathrm{L}$ & $\begin{array}{c}\text { Molecularly Imprinted } \\
\text { Fluorescence Sensor } \\
\text { Thermosensitive } \\
\text { Hepatitis }\end{array}$ \\
HAV & HBV & - & $1.1 \mathrm{pmol} / \mathrm{L}$ & $\begin{array}{c}\text { MIP RLS sensor } \\
\text { Molecularly Imprinted } \\
\text { Fluorescence Sensor }\end{array}$ \\
Hepatitis & HCV & $0.5-90 \mathrm{nmol} / \mathrm{L}$ & $5.3 \mathrm{pmol} / \mathrm{L}$ & $\begin{array}{c}\text { [47] } \\
{[45]}\end{array}$ \\
\hline
\end{tabular}




\section{Adenovirus}

Adenoviruses are considered as nonenveloped, double-stranded DNA viruses linked with a wide range of medical disorders in human beings. Adenoviruses are responsible for gastrointestinal, self-limited respiratory conjunctival diseases [41, 54], hepatitis, pneumonia, and myocarditis in humans. While among children, five to seven percent of respiratory infections are caused by a human adenovirus (HADV) [41]. It can be transmitted via exposure to infected blood or tissue, inhalation of aerosolized droplets, fecal-oral spread, or direct conjunctival inoculation. The infection can be developed from two days to two weeks depending upon exposure to the virus and transmittance mechanism [54]. About eighty-eight different HADV types are recently assembled into seven human adenovirus species, including A to $\mathrm{G}[55]$.

Altintas et al. had designed Adenovirus specific-MIP nanoparticles immobilized on a surface plasmon resonance (SPR), and this was done with the help of glutaraldehyde coupling. MIP was designed using solid support, which is a glass bead in this case for adenovirus template followed by all constituents for molecularly imprinted polymer synthesis to obtain adenovirus-MIP nanoparticles with approximately $260 \mathrm{~nm}$ size $[41,56]$. Fabricated MIP based sensor exhibited excellent sensitivity within the concentration range of $0.02-20 \mathrm{pM}$ and detection limit of $0.02 \mathrm{pM}$ [56].

\section{Japanese Encephalitis Virus}

Japanese encephalitis virus (JEV) is a zoonotic virus transmitted by mosquitos from animals to humans and is the major cause of viral encephalitis, known as Japanese encephalitis (JE). The disease was first reported in Japan and was characterized in
1935 [57, 58]. Despite the effective vaccine development in 1941 and precautionary measures taken, the disease has emerged globally, especially in Southeast Asia and Australia. Annually 50,000 to 175,000 cases are reported leading to the death of more than 10,000 to 15,000 patients. Moreover, JE is considered the most frequent viral encephalitis with a high mortality rate (25 to $30 \%)$ and neuropsychiatric sequel disorders in $50 \%$ of recovered patients [59-61]. People of all ages are affected, but children are exposed more to JE due to their low immunity [62]. Several conventional methods like Enzyme-linked immunosorbent assays (ELISA), virus isolation, reverse transcriptase PCRs (RTPCRs), and neutralization tests are used for the JEV virus. Still, scientists are making efforts to develop more sensitive, selective, and cost-effective methods for the detection of JEV. Among them, electrochemical and biosensors have emerged as the most sensitive and effective tools for virus detection $[58,63$, 64]. Molecularly imprinted polymer-based viruses are being effectively used with several transducing systems to detect viral pathogens, specially JEV with high selectivity [65].

Simple MIPs are highly-selective, but they require complex signaling processes and instrumental confirmation of results. The introduction of fluorescent material into molecularly imprinted polymers can provide fluorescence detection of the specific target [66]. Liang et al. developed a fluorescence sensor for JEV detection on the surface of silica microspheres (SiMP). The surface of SiMP was modified with fluorescence dye (pyrene-1-carboxaldehyde). The fluorescence intensity was enhanced by using a fluorescence energy transfer mechanism in which the virus acted as a donor while the surface acted as an accepter. The intensity was found proportional to virus concentration with a maximum intensity at $960 \mathrm{pM}$. The observed detection limit was $9.6 \mathrm{pM}$ with a relative 
standard deviation of $1.99 \%$ [67]. Feng et al. developed a surface imprinted fluorescent MIP sensor on silica microspheres (SiMP) by using dansyl chloride (DNS-Cl) as a fluorescent material. After immobilization of DNS-Cl on the silica surface, the polymer was generated by mixing the template (JEV), monomer (3-Aminopropyl)triethoxysilane) and tetraethyl orthosilicate (TEOS) crosslinker with the silica microspheres, and the polymerization was performed. After template removal, the cavities were generated and the sensor was exposed to various template concentrations from $1.2 \mathrm{pmol} \cdot \mathrm{mL}-1$ to 960 pmol.mL-1. The sensor was able to detect JEV up to Pico molar concentrations with an equilibrium time of 55 minutes [68]. Using molecular orbital framework (MOF) as supporting material for MIP increases its selectivity and surface area, resulting in enhanced sensitivity and selectivity of the sensor [69]. Yang et al. used a fluorescence MIP sensor based on the molecular orbital framework for JEV detection. The polymer was formed with a free-radical polymerization method on silicon modified MOF surface using zinc acrylate as a monomer. Polyethylene glycol was used as a blocking agent for controlled polymerization and higher selectivity. The polymer responded to a wide range of virus concentrations $50 \mathrm{pmol} \mathrm{L}^{-1}$ to $1400 \mathrm{pmol} \mathrm{L}^{-1}$ with a very low response time of $20 \mathrm{~min}$. The observed detection limit was $13 \mathrm{pmol} \mathrm{L}^{-1}$ under optimal experimental conditions [70]. Magnetic molecularly imprinted polymers (MMIPs) have provided a great advantage over conventional MIPs as they are more sensitive, have low operation time, and provide easy template removal [71]. Luo et al. fabricated a surface imprinted RLS magnetic sensor for JEV detection. The silicon-coated $\mathrm{Fe}_{3} \mathrm{O}_{4}$ microspheres were used as a substrate material, while the polymer was generated around JEV templates using Aminopropyl-triethoxysilane (APTES) as a monomer and polymerization process of Tetraethyl-orthosilicate. The magnetic removal of the template molecules created JEV specific cavities. The sensor exhibited excellent selectivity and sensitivity for the virus with a very low detection limit of 1.3 $\mathrm{pM}$. The sensor had a very low response time and the absorption equilibrium was much lower $(20 \mathrm{~min})$ due to the combined advantages of RLS and magnetic MIPs [72]. The study reveals that the advances in imprinting mechanism and separation technologies the sensitivity and selectivity of fluorescence methods have been much approved. There is a great hope that soon, noninvasive hand-based sensing tools will be available for accurate on spot detection of JEV and associated encephalitis.

Table 4. MIPs for the detection of JEV.

\begin{tabular}{|c|c|c|c|c|c|}
\hline Disease & Template & Linear Range & LOD & Detection method & Ref \\
\hline $\begin{array}{l}\text { Japanese } \\
\text { encephalitis }\end{array}$ & JEV & $20.6 \mathrm{pM}$ to $980 \mathrm{pM}$ & $9.6 \mathrm{pM}$ & $\begin{array}{l}\text { Molecularly Imprinted Fluorescence } \\
\text { Sensor }\end{array}$ & [67] \\
\hline $\begin{array}{l}\text { Japanese } \\
\text { encephalitis }\end{array}$ & JEV & $\begin{array}{l}1.2 \mathrm{pmol} / \mathrm{L} \text { to } 960 \\
\mathrm{pmol} / \mathrm{L}\end{array}$ & $0.4 \mathrm{pmol} / \mathrm{L}$ & $\begin{array}{l}\text { Molecularly Imprinted Fluorescence } \\
\text { Sensor }\end{array}$ & [68] \\
\hline $\begin{array}{l}\text { Japanese } \\
\text { encephalitis }\end{array}$ & JEV & $\begin{array}{l}50 \mathrm{pmol} / \mathrm{L} \text { to } \\
1400 \mathrm{pmol} / \mathrm{L}\end{array}$ & $13 \mathrm{pmol} / \mathrm{L}$ & $\begin{array}{l}\text { Magnetic Molecularly Imprinted } \\
\text { Fluorescence Sensor }\end{array}$ & [70] \\
\hline $\begin{array}{l}\text { Japanese } \\
\text { encephalitis }\end{array}$ & JEV & - & $1.3 \mathrm{pmol} / \mathrm{L}$ & $\begin{array}{c}\text { Resonance light scattering- } \\
\text { Magnetic Molecularly Imprinted } \\
\text { Fluorescence Sensor }\end{array}$ & [72] \\
\hline
\end{tabular}




\section{Picornaviruses}

Picornaviruses are a diverse group of non-enveloped positive-sense, single-stranded RNA viruses comprising more than 110 recognized species divided into 47 genera that may increase with time [73]. These viruses have diverse pathogenicity and affect many animal species and humans. They cause a variety of diseases such as acute or sometimes fatal paralysis, meningitis, myocarditis, poliomyelitis, and encephalitis [74]. They are also a source of foot and mouth infections and several clinically acute vesicular diseases in domestic animals such as ruminants and swine [75]. Quartz crystal microbalance (QCM) transducers have been frequently used to develop molecularly imprinted polymer-based sensors because of their highly sensitive response and structural variability [76]. A QCM based molecularly imprinted polymer sensor was developed by Jenik et al. for the detection of human rhinovirus (HRV) and foot and mouth disease virus (FMDV). Multilayers of polyurethane were generated and, virus imprinted cavities were generated by the stamp imprinting process. The sensor was exposed to various concentrations of virus template, and measurements were recorded. The results suggested that the template shows reversible binding that has a magnitude greater than the non-specific adsorptions. The sensor exhibited a net frequency change of $300 \mathrm{~Hz}$ when exposed to a viral suspension with template concentration of $100 \mu \mathrm{g} / \mathrm{mL}$ with a brilliant signal to noise ratio. The change in frequency was also observed between HRV and FMDV viruses. Different stereotypes of $\mathrm{HRV}$ such as $\mathrm{HRV}_{1} \mathrm{~A}, \mathrm{HRV}_{14}$, and $\mathrm{HRV}_{16}$ were also distinguishable due to different frequency changes by the virus molecules. Thus the proposed sensor proved to be highly sensitive and selective for HRV and FMDV detection and is a pathway to develop reliable sensors for on-spot detection of picornaviruses [77].

\section{Conclusion}

The molecular imprinting technique is an emerging technology for the selective detection of viruses through template-oriented cavities within the polymer matrix. MIPs has advantages over natural antibodies because they are selective, robust, economical, and stable. The world is still suffering from viral syndromes and the most recent pandemic of coronavirus. We also suggest fabricating a MIP-based coronavirus sensor using previous viral detection methods. This can be the most effective and selective sensor for the coronavirus disease diagnosis. Moreover, MIPs have been presented as a novel media for screening inhibitors for drug discovery that might be utilized in the battle against viral diseases. The complex of focal points achieved by the sub-atomic engraving innovation is foreseen to locate its home in the frontlines of future viral investigations.

\section{Conflict of Interest}

The authors declare that they have no conflict of interest.

\section{References}

1. Breitbart, M. and Rohwer, F. Trends Microbiol, 13 (2005) 278.

doi: 10.1016/j.tim.2005.04.003

2. A. Panghal and S. Flora, Bio Warf Pre, 4 (2020) 65 .

doi:10.1016/B978-0-12-812026-

\subsection{4-9}

3. G. Luo and S. J. Gao, J. Med. Virol., 92 (2020) 399.

doi:10.1002/jmv. 25683

4. H. Jeong and B. L. Seong, J. Microbiol., 55 (2017) 220.

doi:10.1007/s12275-017-7371-x

5. J. Oyler-Yaniv, APS Phys., 65 (2020) 1. https://meetings.aps.org/Meeting/MAR2 $\underline{0 / \mathrm{Session} / \mathrm{P} 26.11}$ 
6. World Health Organization, Infectious diseases kill over 17 million people a year: WHO warns of global crisis., (1996).

https://www.who.int/news/item/01-011996-infectious-diseases-kill-over-17million-people-a-year-who-warns-ofglobal-crisis

7. L. W. Riley and R. Blanton, Microbiol. Spectr., 6 (2018) 1.

doi:10.1128\% 2Fmicrobiolspec.AME$\underline{0001-2018}$

8. A. E. Shaw, S. M. Reid, K. Ebert, G. H. Hutchings, N. P. Ferris and D. P. King, J. Virol. Methods, 143 (2007) 81. doi:10.1016/j.jviromet.2007.02.009

9. L. Zhan, W. B. Wu, X. X. Yang, and C. Z. Huang, New J. Chem., 38 (2014) 2935. doi:10.1039/C4NJ00253A

10. M. Parekh, A. Donuru, R. Balasubramanya and S. Kapur, Radiology, 297 (2020) 289. doi:10.1148/radiol.2020202504

11. C. G. Golding, L. L. Lamboo, D. R. Beniac, and T. F. Booth, Sci. Rep., 6 (2016) 1. doi:10.1038/srep26516

12. K. Jung, H. Hu and L. J. Saif, Virus Res., $226(2016) 50$.

doi:10.1016/j. virusres.2016.04.009

13. S. V. Vemula, J. Zhao, J. Liu, X. Wang, S. Biswas and I. Hewlett, Viruses, 8 (2016) 96.

doi:10.3390/v8040096

14. N. T. Darwish, S. D. Sekaran and S. M. Khor, Sens. Actuator B Chem., 255 (2018) 3316. doi:10.1016/j.snb.2017.09.159

15. V. X. T. Zhao, T. I. Wong, X. T. Zheng, Y. N. Tan and X. Zhou, Mater. Sci. Technol., 3 (2020) 237. doi:10.1016/j.mset.2019.10.002

16. G. Qiu, Z. Gai, Y. Tao, J. Schmitt, G. A. Kullak-Ublick and J. Wang, ACS Nano, 14 (2020) 5268. doi:10.1021/acsnano.0c02439

17. J. J. BelBruno, Chem. Rev., 119 (2018) 94.

doi:10.1021/acs.chemrev.8b00171

18. Y. Saylan, S. Akgönüllü, H. Yavuz, S. Ünal and A. Denizli, Sensors, 19 (2019) 1279.

doi:10.3390/s19061279

19. M. Yoshikawa, K. Tharpa and S. t.-O. Dima, Chem. Rev., 116 (2016) 11500. doi:10.1021/acs.chemrev.6b00098

20. M. Rutkowska, J. Płotka-Wasylka, C. Morrison, P. P. Wieczorek, J. Namieśnik and M. Marć, Trends Anal. Chem., 102 (2018) 91. doi:10.1016/j.trac.2018.01.011

21. O. S. Ahmad, T. S. Bedwell, C. Esen, A. Garcia-Cruz and S. A. Piletsky, Trends Biotechnol., 37 (2019) 294. doi:10.1016/j.tibtech.2018.08.009

22. P.S. Sharma, Z. Iskierko, A. Pietrzyk-Le, F. D'. Souza and W. Kutner, Electrochem. Commun., 50 (2015) 81. doi:10.1016/j.elecom.2014.11.019

23. S. Ansari and M. Karimi, Talanta, 167 (2017) 470. doi:10.1016/j.talanta.2017.02.049

24. X. Su, X. Li, J. Li, M. Liu, F. Lei, X. Tan, P. Li and W. Luo, Food Chem., $171(2015) 292$. doi:10.1016/j.foodchem.2014.09.024

25. S. Kunath, M. Panagiotopoulou, J. Maximilien, N. Marchyk, J. Sänger and K. Haupt, Adv. Healthc. Mater., 4 (2015) 1322. doi:10.1002/adhm.201500145

26. S. A. Zaidi, Drug Deliv., 23 (2016) 2262. doi:10.3109/10717544.2014.970297

27. M. Gast, H. Sobek and B. Mizaikoff, Trends Anal. Chem., 114 (2019) 218. doi:10.1016/j.trac.2019.03.010

28. F. Cui, Z. Zhou and H. S. Zhou, Sensors, 20 (2020) 996. doi:10.3390/s20040996 
29. S. Sakinah, S. K. Kumaran, P.-L. Mok, A. Higuchi, G. Benelli and S. S. Kumar, Dengue: A Silent Killer, a Worldwide Threat. In: G. Benelli, H. Mehlhorn (eds) Mosquito-borne Diseases. Parasitology Research Monographs, Springer, Cham. Vol 10 (2018) pp. 23-39. doi:10.1007/978-3-319-94075-5_4

30. M. Trunfio, A. Savoldi, O. Viganò and A. D. A. Monforte, Infection, 45 (2017) 10.

$$
\text { doi:10.1007/s15010-016-0927-6 }
$$

31. World Health Organization. Deng. Sev. Deng., (2017).

https://www.who.int/news-room/factsheets/detail/dengue-and-severe-dengue

32. B. Zhang, G. B. Salieb-Beugelaar, M. M. Nigo, M. Weidmann and P. Hunziker, Nanomed.: Nanotechnol. Biol. Med., 11 (2015) 1745. doi:10.1016/j.nano.2015.05.009

33. W. Sukjee, C. Tancharoen, P. T. Yenchitsomanus, M. P. Gleeson and C. Sangma, Chem. Open, 6 (2017) 340. doi:/10.1002/open.201700037

34. R. Arshad, A. Rhouati, A. Hayat, M. H. Nawaz, M. A. Yameen, A. Mujahid and U. Latif, Appl.Biochem. Biotechnol., 191 (2020) 1384. doi:10.1007/s12010-020-03285-y

35. P. Lieberzeit, S. Chunta, K. Navakul, C. Sangma and C. Jungmann, Procedia Eng., 168 (2016) 101. doi:10.1016/j.proeng.2016.11.157

36. J. L. McAuley, B. P. Gilbertson, S. Trifkovic, L. E. Brown and J. L. McKimm-Breschkin, Front. Microbiol, 10 (2019) 39. doi:10.3389/fmicb.2019.00039

37. H. Zhang and B. L. Miller, Biosens. Bioelectron., 141 (2019) 111476. doi:10.1016/j.bios.2019.111476

38. T. Wangchareansak, A. Thitithanyanont, D. Chuakheaw, M. P. Gleeson, P. A. Lieberzeit and C. Sangma, J. Mater. Chem. B, 1 (2013) 2190.
doi:10.1039/C3TB00027C

39. G. K.-M. Goh, A. K. Dunker and V. N. Uversky, BMC Genomics, 9(2008) 14. doi:10.1186/1743-422X-6-69

40. A. Afzal, A. Mujahid, R. Schirhagl, S. Z. Bajwa, U. Latif and S. Feroz, Chemosensors., 5 (2017) 7. doi:10.3390/chemosensors5010007

41. A. A. Malik, C. Nantasenamat and T. Piacham, Mater. Sci. Eng. C, 77 (2017) 1341. doi:10.1016/j.msec.2017.03.209

42. T. Wangchareansak, A. Thitithanyanont, D. Chuakheaw, M. P. Gleeson, P. A. Lieberzeit and C. Sangma, Med. Chem. Comm., 5 (2014) 617. doi:10.1039/C3MD00272A

43. C. Sangma, P. A. Lieberzeit and W. Sukjee, H5N1 virus plastic antibody based on molecularly imprinted polymers, in Synthetic Antibodies. Springer., (2017) 381. doi:10.1007/978-1-4939-6857-2 24

44. W. Sukjee, A. Thitithanyanont, S. Wiboon-Ut, P. A. Lieberzeit, M. Paul Gleeson, K. Navakul and C. Sangma, J. Biomater. Sci., 28 (2017) 1786. doi:10.1080/09205063.2017.1338503

45. L. Luo, F. Zhang, C. Chen, and C. Cai, Anal. Chem., 91 (2019) 15748. doi:10.1021/acs.analchem.9b04001

46. B. Yang, H. Gong, C. Chen, X. Chen and C. Cai, Biosens. Bioelectron., 87 (2017) 679. doi:10.1016/j.bios.2016.08.087

47. Y. Liu, T. Shen, L. Hu, H. Gong, C. Chen, X. Chen and C. Cai, Sens. Actuators B Chem., 253 (2017) 1188. doi:10.1016/j.snb.2017.07.166

48. D. Lavanchy and M. Kane, Global Epidemiology of Hepatitis B Virus Infection. In: Y.F. Liaw, F. Zoulim (eds) Hepatitis B Virus in Human Diseases. Molecular and Translational Medicine. Humana Press, Cham (2016) pp. 187203. | 
doi:10.1007/978-3-319-22330-8_9

49. Y. Saylan, Ö. Erdem, S. Ünal and A. Denizli, Biosensors, 9 (2019) 65. doi:10.3390/bios9020065

50. L. S. Tang, E. Covert, E. Wilson and S. Kottilil, JAMA, 319 (2018) 1802. doi:10.1001/jama.2018.3795

51. D. W. Al-Sadeq, S. A. Taleb, R. E. Zaied, S. M. Fahad, M. K. Smatti, B. R. Rizeq, A. A. Al Thani, H. M. Yassine and G. K. Nasrallah, Pathogens, 8 (2019) 63. doi:10.3390/pathogens8020063

52. K. Ghanbari and M. Roushani, Sens. Actuators B: Chem., 258 (2018) 1066. doi:10.1016/j.snb.2017.11.145

53. N. Kamar, J. Izopet, N. Pavio, R. Aggarwal, A. Labrique, H. Wedemeyer and H. R. Dalton, Nat. Rev. Dis. Primers, 3 (2017) 16. doi:10.1038/nrdp.2017.86

54. M. G. Ison and R. T. Hayden, Adenovir. In: R. T. Hayden, D.M. Wolk, K. C. Carroll, Y.-W. Tang (Eds) Diagnostic Microbiology of the Immunocompromised Host, Chapter 10, $2^{\text {nd }} \quad$ Edition $(2016) \quad 217$. doi:10.1128/9781555819040.ch10

55. A. Dhingra, E. Hage, T. Ganzenmueller, S. Böttcher, J. Hofmann, K. Hamprecht, P. Obermeier, B. Rath, F. Hausmann and T. Dobner, Sci Rep, 9 (2019) 13. doi:10.1038/s41598-018-37249-4

56. Z. Altintas, J. Pocock, K.-A. Thompson and I. E. Tothill, Biosens. Bioelectron., 74 (2015) 996. doi:10.1016/j.bios.2015.07.076

57. L. Lindquist, J. Travel Med., 25 (2018) 3.

doi:10.1093/jtm/tay006

58. A. Roberts and S. Gandhi, Front. Biosci., 25 (2020) 1875.

doi:10.2741/4882

59. D. E. Impoinvil, M. Baylis, and T. Solomon, Japanese Encephalitis: On the One Health Agenda. In: J. S. Mackenzie,
M. Jeggo, P. Daszak, J. A. Richt (Eds) One Health: The Human-AnimalEnvironment Interfaces in Emerging Infectious Diseases. Springer (2012) 205-247. doi:10.1007/978-3-642-36889-9

60. S.-I. Yun and Y.-M. Lee, Hum Vaccin Immunother, 10 (2014) 263.

doi:10.4161/hv.26902

61. G. L. Campbell, S. L. Hills, M. Fischer, J. A. Jacobson, C. H. Hoke, J. M. Hombach, Bull. WHO, 89 (2011) 766. doi:10.2471/blt.10.085233

62. L. Filgueira and N. Lannes, Pathogens, 8 (2019) 111. doi:10.3390/pathogens8030111

63. E. Khristunova, E. Dorozhko, E. Korotkova, B. Kratochvil, V. Vyskocil and J. Barek, Sensors, 20 (2020) 4600. doi:10.3390/s20164600

64. T. Bharucha, O. Sengvilaipaseuth, M. Vongsouvath, M. Vongsouvath, V. Davong, P. Panyanouvong, G. Piorkowski, J. A. Garson, P. N. Newton and $\mathrm{X}$. de Lamballerie, PloS One, 13 (2018) e0194412. doi:10.1371/journal.pone.0194412

65. R. Kant Upadhyay, Biomed. Res. Int., (2013) 2013. doi:10.1155/2013/591290

66. G. Liu, X. Huang, L. Li, X. Xu, Y. Zhang, J. Lv and D. Xu, Nanomater., 9 (2019) 1030. doi:10.3390/nano9071030

67. C. Liang, H. Wang, K. He, C. Chen, X. Chen, H. Gong and C. Cai, Talanta, 160 (2016) 360. doi:10.1016/j.talanta.2016.06.010

68. W. Feng, C. Liang, H. Gong and C. Cai, New J. Chem., 42 (2018) 3503. doi:10.1039/C7NJ04791F

69. K. Qian, G. Fang and S. Wang, Commun. Chem., 47 (2011) 10118. doi:10.1039/C1CC12935J 
70. J. Yang, W. Feng, K. Liang, C. Chen and C. Cai, Talanta, 212 (2020) 120744. doi:10.1016/j.talanta.2020.120744

71. P. Yáñez-Sedeño, S. Campuzano and J. M. Pingarrón, Anal. Chim. Acta, 960 (2017) 17. doi:10.1016/j.aca.2017.01.003

72. L. Luo, J. Yang, K. Liang, C. Chen, X. Chen and C. Cai, Talanta, 202 (2019) 21.

doi:10.1016/j.talanta.2019.04.064

73. R. Zell, E. Delwart, A. Gorbalenya, T. Hovi, A. King, N. Knowles, A. M. Lindberg, M. Pallansch, A. Palmenberg and G. Reuter, J. Gen. Virol., 98 (2017) 2421. doi:10.1099\% 2Fjgv.0.000911
74. Y. Ao, Y. Zhou, D. Li and Z. Duan, Arch. Virol., 165 (2020) 495. doi:10.1007/s00705-019-04442-3

75. S. Alexandersen, N. J. Knowles, G. J. Belsham, A. Dekker, C. Nfon, Z. Zhang and F. Koenen, Dis of Swine, (2019) 641. doi:10.1002/9781119350927.ch40

76. Y. Uludağ, S. A. Piletsky, A. P. Turner and M. A. Cooper, The FEBS J., 274 (2007) 5471. doi:10.1111/j.1742-4658.2007.06079.x

77. M. Jenik, R. Schirhagl, C. Schirk, O. Hayden, P. Lieberzeit, D. Blaas, G. Paul and F. L. Dickert, Anal. Chem., 81 (2009) 5320. doi:10.1021/ac8019569 